\title{
PRESENTACIÓN
}

\section{HACIA UNA CIUDAD AMABLE Y SOCIAL, ENERGÉTICAMENTE REHABILITADA QUE SE APROXIME DESDE MODELOS COOPERATIVOS A LAS SMARTCITIES EN EL CONTEXTO INTERNACIONAL}

\author{
Prof. Dr. María Luisa Gómez Jiménez \\ Profesora Contratada Doctora (Acreditada Titular) \\ Derecho Administrativo \\ Universidad de Málaga
}

\begin{abstract}
Comenzamos el 2016, con un número, el que el lector tiene en sus manos que aúna investigaciones desarrolladas en el seno del foro Greencities, que tuvo lugar en el Palacio de congresos y exposiciones de Málaga en los días 2 y 3 de octubre de 2015, con propuestas de administrativistas en el contexto nacional y valoraciones de políticas públicas aplicadas en el contexto internacional.
\end{abstract}

Su especial disposición, y selección en propuestas de accesibilidad y rehabilitación es reconducida en esta ocasión desde nuestro tradicional enfoque interdisciplinar hacia la necesidad de pulsar elementos significativos de la sostenibilidad urbana, desde intervenciones en vivienda y en suelo que hagan posible no sólo la calificación de una ciudad como smartcity (cuando es el caso) sino que haga converger los parámetros de mejora de la eficiencia energética y de la atención a los procesos de mejora y regeneración en el espacio Urbano. Es por ello por lo que el conjunto de los trabajos que aquí encontrará le aproximarán a la sugerente reflexión sobre la ciudad como ente complejo e integrador o más bien catalizador de procesos que acontecen - en sintonía con los acontecimientos económicos y sociales pero que precisan de una modulación adaptada a la necesidad de preservar una sostenibilidad social, medioambiental y urbanística.

Este es el caso del trabajo que nos presenta el Arquitecto Hernández Pezzi, que bajo el título "La energía como paradigma del ámbito urbanístico y ambiental", revela desde lo que ha dado en llamar una "bulimia legislativa urbanística" un collage de ideas, que como palimpsesto enfatiza la importancia de una actuación integrada en el medio urbano, desde el "urbanismo energético", y que nos plantea un repaso a las grandes cuestiones y problemas a abordar como lluvia de ideas para descender en la necesidad de confrontar sempiternos retos en el espacio urbano, desde la Agenda Local 21 de Málaga aprobada en el mes de mayo de 2015. Quizás por ello, la

WPS RI-SHUR, nํㅜ, 2016, vol.1, ISSN: 2387-1768 


\title{
WPSReview International on Sustainable
}

\author{
Housing and Urban Renewal (RI-SHUR)
}

premonitoria cita de Galeano, con la que inicia su trabajo, dirige nuestros pasos hacia un camino utópico e inacabado al que los grandes objetivos del Milenio de la ONU, "Conferencia Mundial United Nations Conference on Housing and sustainable urban development Habitat III", que tendrá lugar en Quito en octubre de 2016, y la Estrategia Europea 2020 nos abocan.

La ciudad deberá entonces revelar su lado más amable, como nos anticipan los investigadores de la Universidad de Sevilla que en el marco del proyecto GGI3001/IDIU de la Consejería de Fomento y Vivienda de la Junta de Andalucía vienen a presentar un análisis exhaustivo de la eficacia de las políticas públicas en general y del programa la ciudad amable en particular. El programa la Ciudad amable, iniciativa promovida en 2013, por la Consejería de Fomento y Vivienda, a través de la Dirección General de Rehabilitación y Arquitectura, en colaboración con la Dirección General de Movilidad y la Dirección General de Infraestructuras, fue preseleccionado a nivel nacional por el Comité Hábitat Español del Ministerio de Fomento como una de las seis mejores prácticas urbanas del país, dentro del programa de las Naciones Unidas para los Asentamientos Humanos -ONU-Hábitat-, compitiendo para optar al Premio Internacional de Mejores Prácticas para la Mejora de las Condiciones de Vida de Dubai 2014, quedando entre las finalistas dentro de la categoría Best. Sobre su proyección en el contexto nacional y local, y sobre su originalidad y contenidos nos ilustran sus autores, en una dinámica de proyectos y funcionalidades que no desconoce la participación ciudadana,- integrada a través de fases formativas e informativas, e incorporando una propuesta de buenas prácticas a tener presente en la intervención en la ciudad.

Intervención que precisa además de una adecuada herramienta para maximizar su eficiencia. Esto nos lo revela otra interesante propuesta de la mano de los investigadores del Instituto Habitat en atención a las cooperativas vecinales y la olvidada gestión cooperativa como instrumento para la rehabilitación y conservación de barriadas. Lo interesante de la propuesta se conecta entonces con la recuperación de técnicas jurídicas que han sido relegadas a un segundo lugar en nuestra historia reciente y que en los procesos de rehabilitación y regeneración urbana deben ser recuperadas con el fin de ofrecer respuestas integradas a problemas sociales en los que la participación ciudadana se torna imprescindible. En este contexto, se explora en el texto los modelos de gestión colaborativa en conservación y rehabilitación de barridas, introduciendo el valor añadido que supone el enfoque bottom up, en el que se interviene de abajo-arriba. Se trata de poner en valor las experiencias de cohousing (o co-vivienda), conocerlas mejor para proponer actuaciones que permitan mejorar la actuaciones en rehabilitación integral de espacios urbanos y a la luz de la frescura que incorpora el análisis de los casos examinados por los autores, perfilar una propuesta a nuestro entender de valía que deba ser tenida en cuenta por los operadores jurídicos para su implementación normativa y real. Pues, se anticipa en el texto esa necesidad de profundizar en una figura que si bien es conocida en nuestro ordenamiento jurídico, no se ha proyectado hasta la fecha en el ámbito de la WPS RI-SHUR, nำ, 2016, vol.1, ISSN: 2387-1768 


\section{WPSReview International on Sustainable \\ Housing and Urban Renewal (RI-SHUR)}

regeneración urbana, como si lo ha hecho por el contrario en el contexto internacional de la mano de figuras similares de atención a la integración de la economía colaborativa en la provisión de vivienda.

Es justo esta proyección internacional - no abundamos en las valoraciones que en escenario europeo proyecta ciudades como Zúrich, a las que nos referíamos en la editorial anterior-, sino en esta ocasión a una necesidad de atención social que impregnan dos de los trabajos que completan este número. El primero desde el ámbito de la sociología nos desvela una realidad que a modo de foto fija viene a deslindar la creación misma de los hogares unipersonales en nuestro país. La cuestión no puede ser más actual, y la oportunidad mayor, para dibujar un escenario de intervención administrativa y de proyección edificatoria dispar. $Y$ es que la sociedad española ha cambiado, desde la misma composición de los átomos sociales que son las unidades familiares derivando en nuevas necesidades de vivienda y espacios urbanos. Quizás, en ese condicionamiento económico que marca también una nueva forma de entender el espacio urbano y sus usos y que tanto reflejo proyecta en el seno de debates no ya sociológicos sino arquitectónicos. Así la radiografía de los hogares unipersonales la realiza el Dr. Vallejo, sociólogo, y a la sazón miembro de la Junta directiva de la Asociación Andaluza de Sociología, prestando especial atención a la tipología edificatoria que conlleva el nuevo modelo de hogar unipersonal. $Y$ finalmente, la Doctora Suarez Ojeda, Profesora de Derecho Administrativo de la Universidad Complutense, retoma la cuestión social desde la proyección tecnológica en el entorno urbano de la mano del examen de la accesibilidad en las Smartcities. Su ensayo anticipa cuestiones que conectan la proyección de la intervención administrativa en un escenario complejo del que todos formamos partes en nuestra vida en la ciudad. Ciudades que como ecosistemas vivos precisan de una atención y estudio al que este ejemplar aspira a contribuir.

En Zúrich, a 8 de Julio de 2016

WPS RI-SHUR, n3, 2016, vol.1, ISSN: 2387-1768 